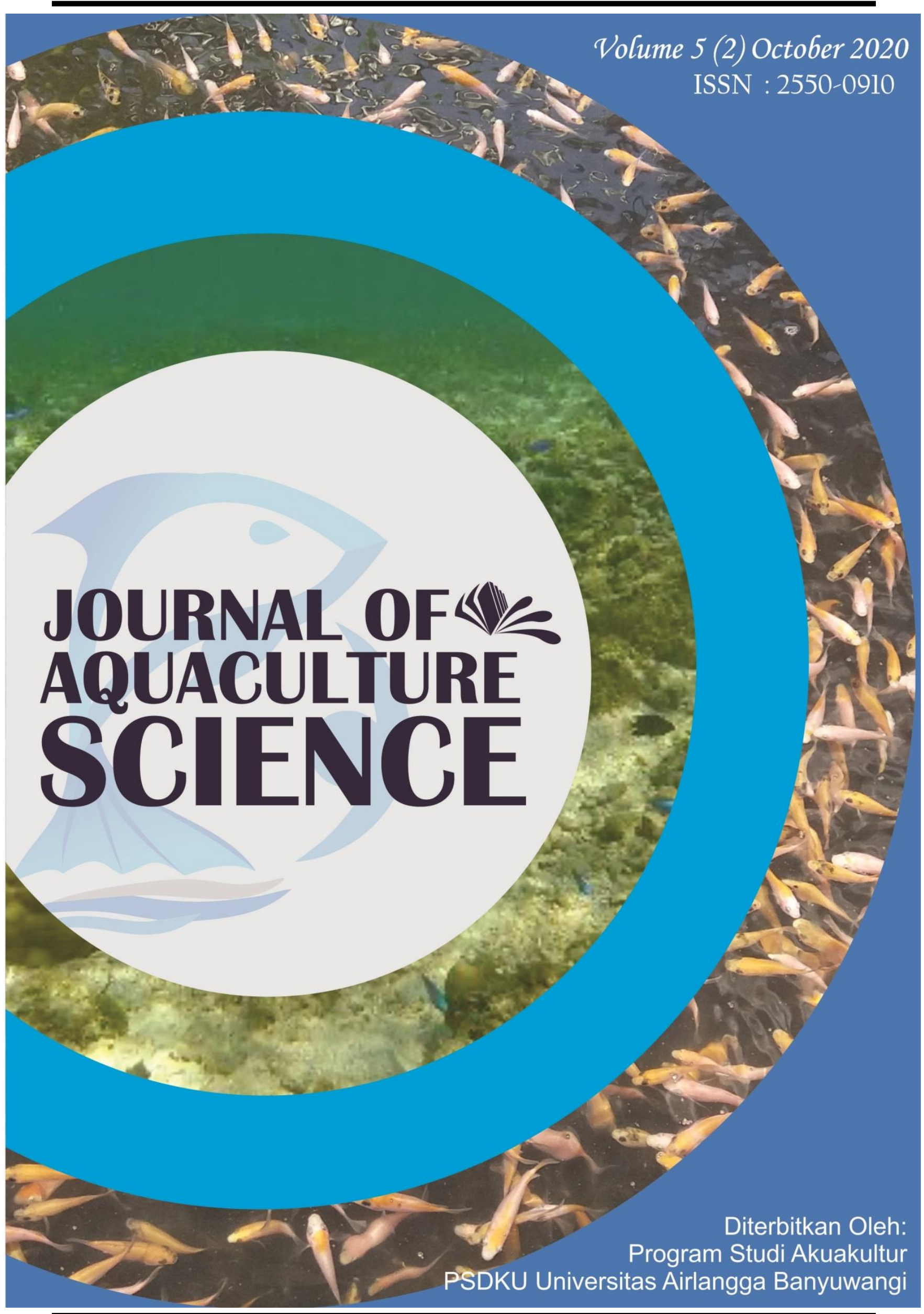




\section{SINTA RISTEKDIKTI}

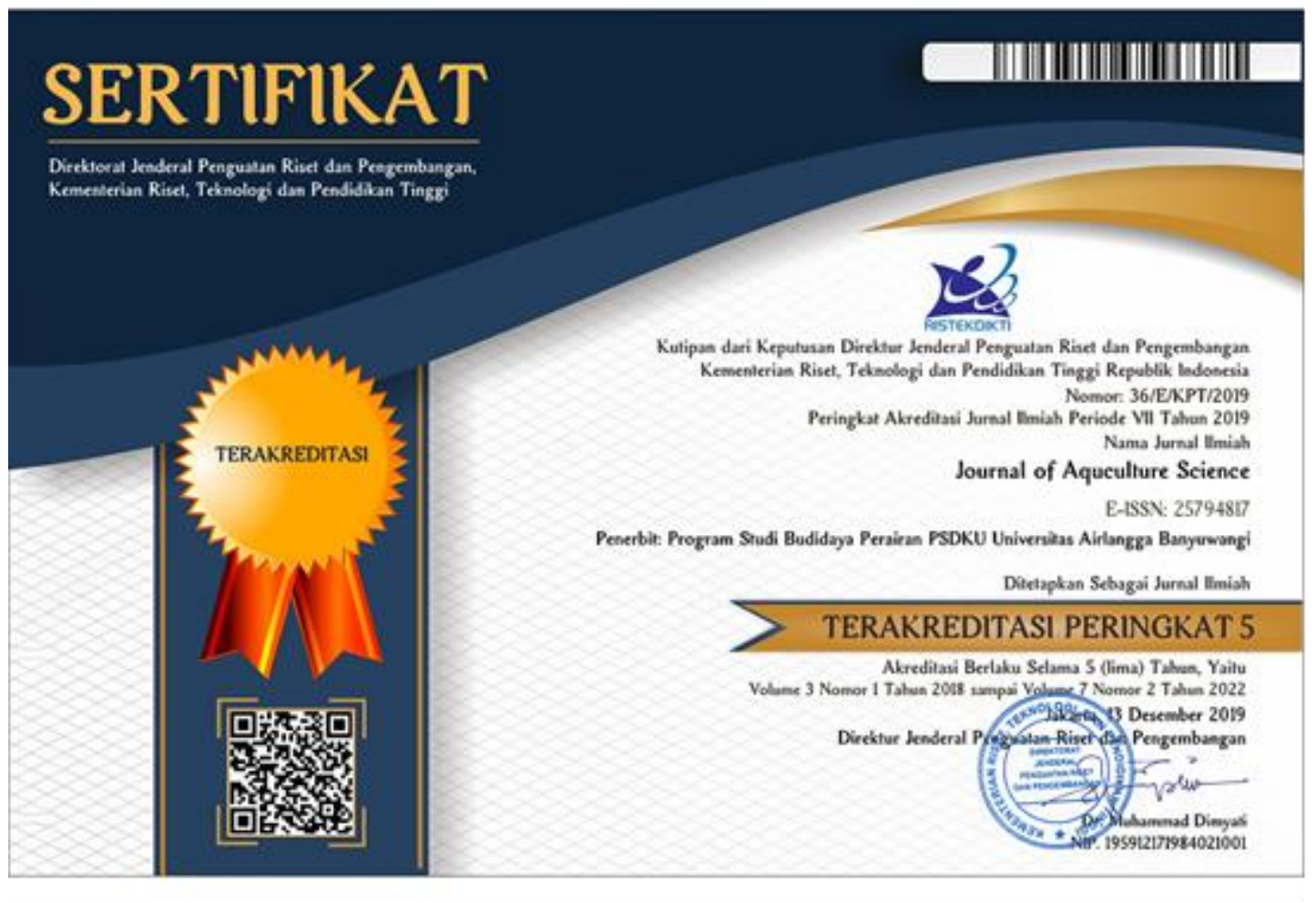

\section{KERJASAMA PENERBIT}

\section{Journal of Aquaculture Science}

Kerja Sama

Fakultas Perikanan dan Kelautan, Universitas Airlangga

\section{ALAMAT REDAKSI}

J1. Wijaya Kusuma 113 Giri, Banyuwangi, Jawa Timur, Indonesia, 68425 Telp: 0333-417788, Fax: 0333-428890

e-mail: joas@psdku.unair.ac.id

Homepage: http://joas.co.id/index.php/JoAS/index

\section{DEWAN REDAKSI}


Ketua Dewan Redaksi

Prayogo, S.Pi., M.P., Universitas Airlangga, Indonesia

Asisten Dewan Redaksi

Suciyono, S.St.Pi., M.P., Universitas Airlangga, Indonesia

Hapsari Kenconojati, S.Si., M.Si., Universitas Airlangga, Indonesia

Abdul Qadir Jailani, S.Pi., M.P., Universitas Tidar, Indonesia

\title{
Anggota Dewan Redaksi
}

Lailatul Lutfiyah, S.Pi., M.Si., Universitas Airlangga, Indonesia

Arif Habib Fasya, S.Pi., M.P., Universitas Airlangga, Indonesia

\author{
Staf Administrasi \\ Choirun Nisa, S.IIP, Universitas Airlangga, Indonesia \\ Rizki Dwi Akbar, Universitas Airlangga, Indonesia
}

\section{MITRA BESTARI}

Terima kasih kepada mitra bestari yang membantu memberikan review dan menilai pada Journal of Aquaculture Science

Prof. Dr. Mirni Lamid, drh., M.P., Universitas Airlangga, Indonesia

Dr. Endang Dewi Masithah, S.Pi., M.P, Universitas Airlangga, Indonesia

Dr. Waode Munaeni, S.Pi., M.Si, Universitas Halu Oleo, Kendari, Indonesia

Dr. Mugi Mulyono,S.St.Pi, M.S, Poltek AUP Jakarta, Indonesia

Dr. Putut Har Riyadi, S.Pi., M.Si, Universitas Diponegoro, Indonesia

Dr. Ruly Isfatul Khasanah, S.Si., M.P, UIN Sunan Ampel Surabaya, Indonesia

Dr. Ir. H. Samliok Ndobe, M.Si, IPM., Universitas Tadulako, Palu, Indonesia

Dr. Aris Widagdo, A.Pi., M.Si, Politeknik Kelautan dan Perikanan Karawang, Indonesia

Dr. Wendy Alexander Tanod, S.Kel., M.Si., Sekolah Tinggi Perikanan, Palu, Indonesia.

Dr.Ir. Evron Asrial, M.Si., Universitas Mataram, Indonesia.

Dewi Nurhayati, S.Pi., M.Si, Universitas 17 Agustus 1945 Cirebon, Indonesia

Apriana Vinasyiam, S.Pi., M.Sc, Institut Pertanian Bogor, Indonesia

Arafik Lamadi, S.ST., M.P, Universitas Negeri Gorontalo, Indonesia

Darmawan Setia Budi, S.Pi., M.Si, Universitas Airlangga Banyuwangi, Indonesia

Wiwin Kusuma Atmaja Putra, S.Pi., M.Si, Universitas Maritim Raja Ali Haji, Indonesia

Rizal Akbar Hutagalung, S.Pi.,M.P, Politeknik Negeri Pontianak, Indonesia

Mohammad Faizal Ulkhaq, S.Pi., M.Si, Universitas Airlangga Banyuwangi. Indonesia

Gde Raka Angga Kartika, S.Pi.,M.P, Universitas Udayana, Indonesia

Muhammad Hanif Azhar, S.Pi., M.Si, Universitas Airlangga Banyuwangi, Indonesia 


\section{VISI DAN MISI}

Journal of Aquaculture Science (JoAS) terdaftar dengan nomor p-ISSN: 2550 - 0910, eISSN: 2579 - 4817, yang diterbitkan oleh Program studi Akuakulture, Fakultas Perikanan dan Kelautan, Universitas Airlangga.

Journal of Aquaculture Science (JoAS) telah terakreditasi oleh Direktorat Jendral Penguatan Riset dan Pengembangan, Kementrian Riset, Teknologi, dan Pendidikan Tinggi, Republik Indonesia dengan Nomor: 36/E/KPT/2019 berlaku sejak 29 April 2018.

Journal of Aquaculture Science (JoAS) adalah menyajikan artikel hasil penelitian, ulasan artikel, komunikasi singkat dan laporan teknis seputar Ilmu Perikanan dan Kelautan yang terbit dua kali setahun (April dan Oktober). Journal of Aquaculture Science merupakan media bagi peneliti, mahasiswa dan praktisi perikanan. Seluruh pemuatan artikel yang diterbitkan oleh Journal of Aquaculture Science melalui sistem Open Journal System (OJS). Informasi seputar pemuatan artikel dan petujunk penulisan tersedia dilaman website: https//joas.co.id.

\section{VISI}

Menjadi jurnal bereputasi nasional dan Internasional dalam bidang perikanan

\section{MISI}

1. Sebagai media perkembangan intelektualitas bagi civitas akademika dalam mendukung Universitas Airlangga menjadi World Class University;

2. Menyelenggarakan pengelolaan jurnal yang akuntabel dan berkualitas untuk meningkatkan jumlah produk intelektual berupa jurnal ilmiah;

3. Menjadi referensi unggulan bagi civitas akademika dan peneliti bidang perikanan kususnya budidaya perairan.

Lingkup Jurnal, budidaya perairan, reproduksi dan penyakit ikan, lingkungan budidaya dan perairan, dan biotechnology.

Bahasa Utama: Bahasa Indonesia

Tambahan: Bahasa Inggris

Artikel yang diterima oleh Journal of Aquaculture Science (JoAS) adalah:

1. Original Artikel

2. Artikel review

3. Short Comunication

4. Technical note 